\title{
Internet Use and Social Capital: The Case of Filipino Migrants in Japan
}

\section{Reggy Capacio Figer, Nagoya University of Commerce and Business, Japan}

\begin{abstract}
This paper explores how Internet use may result in the cultivation of social capital. It takes as its focus Filipino migrants in Japan to prove that Internet use may bring about the creation, maintenance, and enhancement of social capital in the process. Using a Likert-type 5 point scale survey, findings reveal a significant consequence on the majority of social capital items which include Filipinos getting to know each other, an easier lifein Japan, feeling proud of their national identity and belonging to a community. However, trust online is considered by Filipino migrants to be unimportant aspect of social capital. Nonetheless, a relatively high reliability was found in Cronbach's Alpha that covers Internet useand social capital respectively. It can be surmised then that there is a positive relationship between Internet use and social capital amongst Filipino migrants in Japan. Discussed in this paper also are the latent drawbacks and potential research trajectories of the study.
\end{abstract}

Keywords: Filipino migrants, Internet use, online communities, social capital 


\section{Introduction}

The Internet is rapidly becoming a medium of communication technology utilized by people across the world. The number of Internet users worldwide has dramatically grown since its induction to the public. As of December 2011, the Internet World Statistics (2011) estimate that there are about 2.2 billion people who are Internet users. The International Telecommunication Union (2011), meanwhile, approximates that with 7 billion people in the world, one third are using the Internet. These figures indicate how Internet use has become a pervasive activity among people.

One of the major consequences of the Internet on people's lives is how it transforms and changes their ways of interaction with others. This premise is best encapsulated in Marshall Mcluhan's (1964) medium theory in which oral, written, electronic and now the Internet, notwithstanding what is communicated, influence individuals and society (Littlejohn and Foss, 2004). Clearly, the introduction of the Internet has had different effects and impacts on people's communication. In interpersonal contact, for example, the Internet has afforded a variety of different methods for communication. These are email, online chatting, bulletin board system (BBS), web blogs, and online communities. These modern modes or dimensions for contact with others provide venues for people to have dialogue or discussion on the Internet. The Internet is now seemingly a way of life for people as more and more are actively going online and getting involved with various virtual activities. The Information age or Network Society, as Castells (2000) describes it, has swept the world by storm, so to speak.

The Internet also has become a haven for communities to proliferate. Howard Rheingold's (1993) pioneering study on the virtual community establishes the belief that many people utilize the Internet as a means to foster relationships and build communities. Rheingold's work explores how members from the San Francisco area have related personal information about themselves to others through the computer-mediated-communication (CMC). Nancy Baym's (2000) research, meanwhile, underscores the study of online communities and their social interactions brought forth by participants' shared affinity for television operas. Her work provides the notion that fans can connect within a social network or community to create friendships as well as forge ties. Aside from these, the Internet has sparked interest among scholars and researchers about how it can forge the production of social capital 
(Putnam, 2000; Felander, 2003; Ellison, N.B., Steinfield, C., \&Lampe,C., 2007). As definedby Lin (2001) and Putnam (2004), social capital is the available resource that people have through their social interactions. Hence, individuals with a sizeable and sundry network of contacts are believed to have more social capital than those with little and less diverse networks (Valenzuela et.al., 2009). And through Internet use, different dimensions of social capital such as networks, trust, social interaction, social support, norms and life contentment (Lin, 2001; Putnam, 2004)) are cultivated, maintained or enhanced. For this reason, this paper endeavours to explore how Filipino migrants in Japan use the Internet through two online communities. It also tries to investigate how these online communities are appropriated to foster migrants' social capital.

\section{Filipino Migrants in Japan and the Internet}

The Philippines has long been regarded as a migrant-exporting country (Ribas, 2008). Studying the migration patterns through history indicates that Filipinos have been in constant emigration in and around the globe. During the Spanish period, their forebears signed up as members of the Spanish squadron, while others travelled to Spain for education (Abrera-Mangahas, 1987 in Ballescas, 2003). When the Americans came to rule, some Filipinos went to the US to study and train, while others offered cheap labour to Hawaiian plantations, California Farms and Alaska fishing industry (Alegado, 1996). By the mid-70s, another wave of Filipinos worked in Taiwan, Hong Kong, Singapore and Japan (Catholic Institute for International Relations, 1987). An increase in the number of Filipinos moved to Japan because of Japan's economic boom (the Izanagi boom in 1965-1970 and Heisei boom in 1986-1991) and the labour shortages that Japan encountered (Onuki, 2009; Anderson, 1999). Japan as an aging society is also a substantial factor (McCreedy, 2003), hence the need for foreign workers. Because of this, Filipinos together with other foreign nationals (Koreans, Chinese, Brazilian and among others) tried their luck by migrating to Japan and incorporated themselves within the Japanese society.

Based on statistics from 1980 onwards, the female populace continues to be the majority among the growing number of Filipino migrants in Japan (Onuki, 2009; Ballescas, 2003). Among the largest visa category admitted for Filipino women were "entertainers". Looking for better economic opportunities and at the same time to advance their social status in the Philippines, Filipino women went to Japan in significant numbers by the early 1980s 
(Anderson, 1999). They worked as cultural dancers, vocalists and hostesses in clubs and bars. According to Shimada (1994, p.15): "more than half of all foreign workers are classified as entertainers...the majority of these....are singers and dancers...most of them women from the Philippines" (in Anderson, 1999, p. 2). Because of the nature of the job, consequently, most Filipino migrants are young (Ballescas, 2003). Most recently, Japan has also opened its doors to Filipino nurses to take charge of caring for their elderly and children (Melican, 2010).

Japan's economic stability and the rise of the Japanese yen since the 1970s (Matray, 2000), the negative mind-set of young Japanese on kitanai (dirty), kiken (dangerous) and kitsui (difficult) jobs (Connell, 1993) and labour shortages because of the decline in the population growth and an increase in the Japanese elderly (Hewitt, 2003; Usui, 2003) are some of the signifcantfactors that attract Filipinos as well as other foreigners to work in Japan.

For this reason, Filipinos working abroad acquire financial solidity, and their families, who are left behind in the homeland gain economic benefits from this. In exchange for these financial rewards, Overseas Filipino Contract Workers (OFWs) have to cope with physical and emotional troubles. In the host society, OFWs are confronted with profound stresses from internal and external sources. As Parrenas (2001) reasons, the "pain of family separation, partial citizenship, the experience of contradictory class mobility and the feeling of social exclusion or non-belonging in the migrant community" (p.12.) and host societies are consequences to the dislocation of Filipino migrants.

For migrants to survive, they (re)create their cultural identities in their host societies. They use and engage with old and mass media. Some participate in religious and cultural organizations that afford their communal activities. The emergence, however, of new technology and media, has instigated OFWs to be more interactive from great distances. As Parham (2004) underscores, the Internet has become a fundamental medium for diffusegoups to maintain an identity in an "alien" land while working in unanimity with those at "home" (p. 199).

This is to say that in their quest to incorporate into the host society, communication and media - old and new - are utilized to connect and network in the host and homeland 
societies. As technology advances and develops, Filipino migrants become interactive across huge distances. The Internet nowhas become a daily form of haven to receive information and social support from various individuals, from within the host country or otherwise. As such, globalization is regarded as a boon when it comes to the integration of nations and states becoming an international federation.

According to Diamandaki (2003), the Internet is a good venue for social networks and collective belonging among people from different upbringings and origins. This paper then presupposes that OFWs in Japan utilize the Internet for communication, connection and linkage between and among fellow migrants. It is assumed that through this Internet use, social capital will be developed and enhanced.

This presupposition is moreover substantiated by Waldinger \& Lichter (2003) as they adhere to the idea that through social networks, and critical and important resources from both the host and home countries, migrants are able to cultivate social capital. It can be surmised then that social capital is developed and enhanced through the social interactions between individuals and groups. OFWs use their sense of connection and affinity through their engagement with the cyberworld. It is argued then that the Internet is an interactive means to connect and bond people and consequently has the potential to play a positive and constructive role in building and fostering social capital and communication. This paper ascertains the relationship of Internet use, communication and social capital among Filipino migrants in Japan. It brings to the fore how Filipinos capitalized on the potential of the Internet in order to develop and cultivate social capital and communication.

\section{Methodology}

This paper is grounded in quantitative research; hence the use of surveys to collect data is apposite. It should be noted, however, that the survey was conducted online with two cybercommunities. These are Timog Online and Malago.net. Timog Online and Malago.net are online forums that cater for Filipino migrants in Japan. Membership is open, quick and anonymous. It is open because anyone can join the site. It is quick because registration only takes a couple of seconds and one can instantly participate in forums. And it is anonymous because the site does not require identification of its members. Forum moderators maintain the order of these sites and keep track of themes or topics for discussion. The moderators 
arealso the ones who reply to any questions regarding sites operations. A member can post messages addressed to moderators.

These online communities are public sites and therefore can be accessed by anyone. However, to take part in a conversation and get access to messages, one must log-in. Therefore, a visitor has to create an account with the site and create a panel name (pseudonym) of his/her choice.

Below are screen shots of Timog.com and Malago.net.

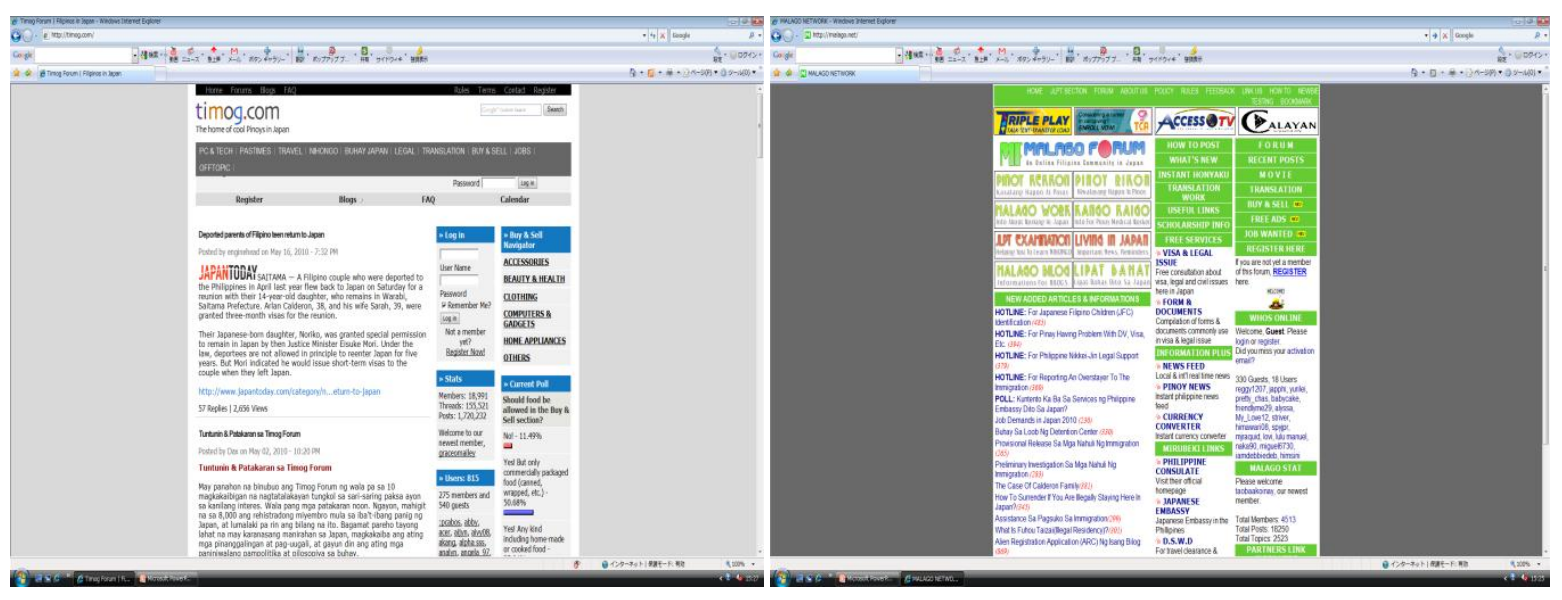

Figure 1. Screen Shots of Timog.com (see top) and Malago.net (see bottom)

This paper, as mentioned above, utilized online surveys as method. This is to ascertain if there is a significant relationship between Internet use and social capital. This entailed looking into the profile of respondents and their outlook towards Internet use, communicationand social capital.

The survey was created through Google Documents. This completely free program is loaded with capability to construct documents, spreadsheets, and presentations and recently survey forms. After creating the survey, Google Documents collected all responses and stored them in Google Documents Spreadsheets. It also provided a frequency distribution of each question in the survey. Below is a screenshot of the online survey. 


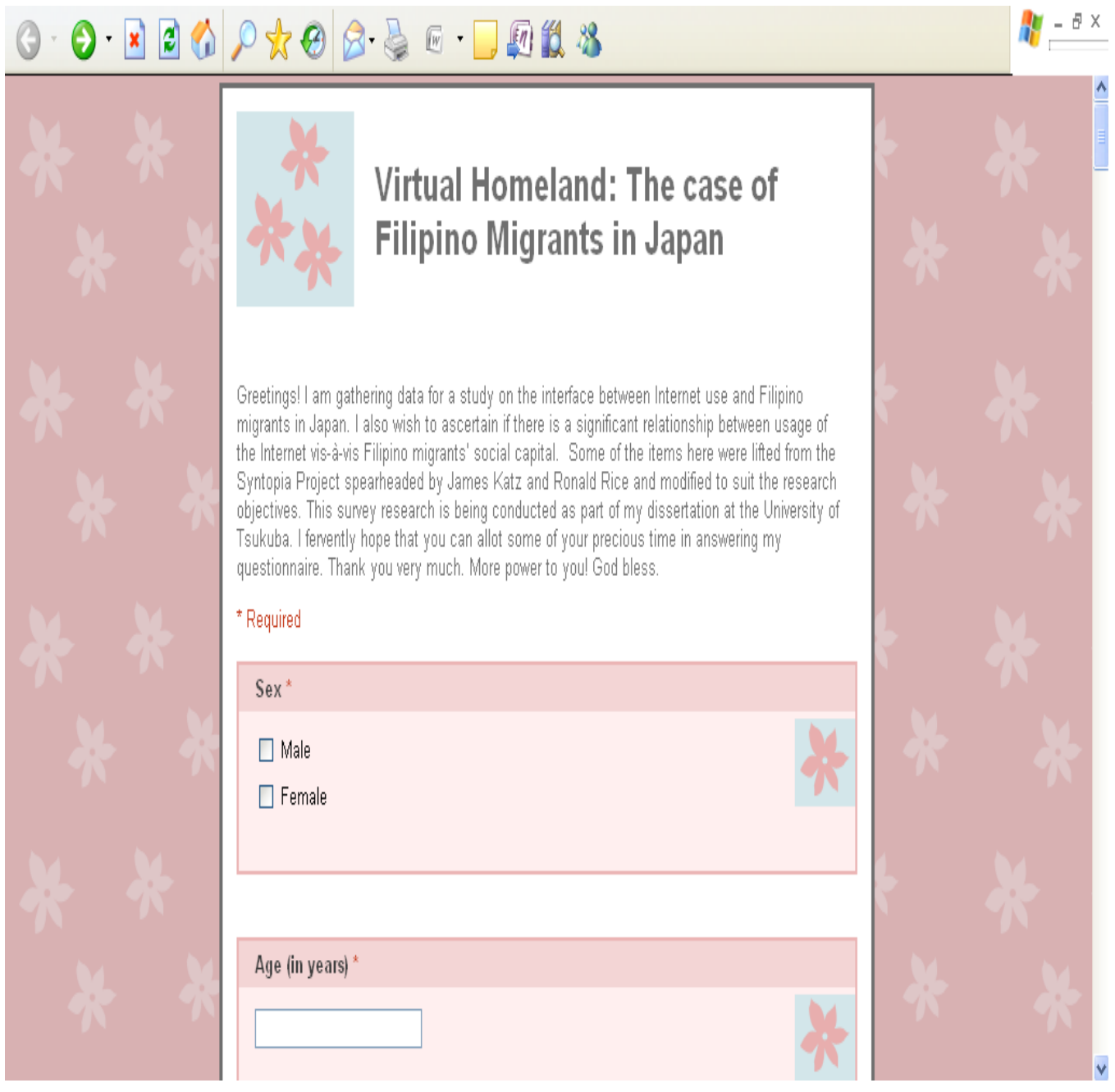

Figure 2. Screen shot of the Online Survey

Most of the items in the survey were from the Syntopia Project, a series of national random telephone surveys that charted social aspects of American's Internet behavior and tracked social and community aspects of Internet use (Katz, J.E. \& Rice, R..E., 2002).James E. Katz and Philip Aspeden headed this project. The surveys were fielded in 1995, 1996, 1997 and 2000 with some variations or revisions in the questionnaires of each year to respond to the changing times (Katz \& Rice, 2002).

This paper utilizes items from the Syntopia survey butthe questionnaires were reviewed and modified to suit the purpose and objectives of the study. The modified version of the questionnaire was pre-tested informally, originally concentrating on individual questions. Eight Filipino students of the University of Tsukuba, Japan were approached to read the questionnaire. They provided constructive comments on the wording and improvements 
ofthe questionnaire. Were the questions clear, simple and unambiguous? (Robson, 2002) These were the points that guided their examination of the questionnaire. Comments were incorporated and provided latitude to a clearer and understandable survey questionnaire.

SPSS (Statistical Package for the Social Sciences) was used to ascertain respondents' profiles and the relationship between Internet use and social capital. Data analysis commenced with a basic reading of univariate tables, then, proceeded with bivariate tests using some demographic profile as independent variables. Chi-Square Test of Independence was used in cross-tabulating the independent variables with categorical measures. For the scales, T-test of Independence and Analysis of Variance were used. In all these tests, the significance level was set at $\mathrm{p}<.05$.

\section{Results and Discussion}

The survey was conducted from January 2010 to June 2010. Initiallly, the survey questionnaire was posted on one of the message boards of Timog.com and Malago.net, as suggested by one of the senior members of Timog.com. He believed this would facilitate easy feedback from members since one can readily see it posted on the bulletin board. Unfortunately, this became ineffective since only 5 participated in the survey. The researcher then resorted to sending the questionnaire to each member who was online. Everyday, the researcher would check who was online and send questionnaire through their message accounts. A month was alloted to this activity. Some 1,000 questionnaires were sent, only 57 replied and sent back their answers, 2 of which were spoiled because of inadequate answers. After some consultations with experts on survey, an online survey was contsructed through the use of Google Documents. The link of the survey was posted in both online communities, which yielded 28 responses. The final total of answered questionnaires was 90. No monetary incentive was given to those who answered the survey. It should be noted that the sample is a small portion of the total population of Filipino migrants in the world. The cross-section was concentrated from those living in Japan. The sample is relatively significant in online surveys since it did not give any incentive to respondents (Mann \& Stewart, 2005). It was through their own volition that they participated in the online survey. 
Respondents for this paper were online members from Timog.com and Malago.net. Most of the respondents who took time to answer the online survey were females (59\%). This may mean that most likely there are more female members in online communities. This finding could correspond to Onuki's (2009) and Ballescas' (2003) studies that Filipina women continue to be the majority among the growing number of Filipino migrants in Japan.

Agewise, the 24-29 (40\%) and 30-35 (31\%) age brackets were in the majority. Because of the nature of work (i.e. entertainers, English teachers, IT and factory workers), most of the Filipino migrants were young and single (54\%). Moreover, a large portion of the respondents were Roman Catholic (94\%). This is primarily because the majority of the population in the Philippines is Roman Catholic. Likewise, college graduates comprised half of the respondents (51\%) of the survey. This relates to Collado's (2003) research that Filipinos were more educated than their Asian counterparts when they go abroad for work. Most of the respondents were somehow new in Japan, extending from 1-5 years (73\%). This period implies adjustment for most of the migrants; hence their enthusiasm and zest to know the host country and to get connected online with other fellow migrants is high.

Table 1 presents the detailed profile of respondents online.

Table 1. Profile of
Respondents $(\mathrm{N}=90)$

\begin{tabular}{lll}
\hline Sex & Frequency & Percent \\
\hline Male & 37 & 41 \\
Female & 53 & 59 \\
Age (in years) & & \\
$18-23$ & 8 & 9 \\
$24-29$ & 40 & 44 \\
$30-35$ & 31 & 34 \\
$36-41$ & 7 & 8 \\
42 and over & 4 & 4 \\
Religion & & \\
Roman Catholic & 85 & 94
\end{tabular}


Iglesiani Cristo

Protestant

Marital Status

Married

Single

Separated/Widow/er

Educational level

High School

Some college/vocational

College/Postgraduate

Monthly income range

Less than 100,000 yen

100,000-150,000

$150,001-200,000$

200,001-250,000

250,001-300,000

Over 300,000

\section{3}

2

38

49

4

9

30

51

15

17

25

12

6

14
3

2

42

54

4

10

17

19

28

13

7

16

Total number of years in

Japan

1-5

73

81

$6-10$

14

16

$11-15$

2

2

$16-20$

1

From the sample of 90, 53 percent responded using a personal computer at home, work or school. Respondents believed that their Internet skill level is on the side of above average (47\%) and average (38\%) which gave them the ability to navigate more than just basic applications on the Internet. From the following reasons, based on a three-point scale, listed in the online survey, respondents believed that all the reasons were very important for them in becoming an Internet user: send and receive email (87\%), find out information about special interests (69\%), nowadays it is just a good thing to do (59\%) and have contact with new people (49\%). Relatively, respondents spent more than 10 hours online in the last 
seven days. Hence, one could assume that most of the respondents were heavy users of the Internet.

Mean and SD for Internet and social capital items are in Table 2.

Table 2 Means and Standard Deviations (SD) for Internet Items ( $\mathrm{N}=90$ )

\begin{tabular}{lll} 
1.) From online forums, do you ever get news? & 3.82 & 1.27 \\
2.) From online forums, do you ever get financial information? & 2.62 & 1.32 \\
3.) From online forums, do you ever look for information about product? & 3.69 & 1.15 \\
4.) From online forums, do you ever get information about travel? & 3.76 & 1.06 \\
5.) From online forums, do you ever do research for school or training? & 3.72 & 1.45 \\
6.) From online forums, do you ever look for health and medical information? & 3.73 & 1.24 \\
7.) From online forums, do you ever look for jobs available? & 3.89 & 1.33 \\
8.) From online forums, do you ever look for religious or spiritual information? & 3.14 \\
9.) From online forums, do you ever ask for advice on visa and legal issues? & 1.36 \\
10.) From online forums, do you ever express opinions/sentiments about Philippines/Japan on the Net? & 3.64 \\
11.) From online forums, do you ever use the Internet for love and romance? & 3.14 \\
B. Social Capital & 3.39 \\
1.) Have online forums helped you to get to know more Filipinos? & 3.46 \\
2.) Do you trust people from online forums? & 1.33 \\
3.) Do you belong in a community, thanks to online forums? & 4.17 \\
4.) Are you active in local communities because of online forums? & 3.06 \\
5.) Do you feel proud to be Filipino because of online forums? & 3.92 \\
6.) Are you more religious because of online forums? & 3.16 \\
7.) Is living in Japan easier, thanks to online forums? & 3.18 \\
\hline
\end{tabular}

From these results, the following were potentially appealing uses of the Internet communication among respondents: looking for jobs, news, travel travel, health and medical information, school or training research, product information, and visa and legal issues, to thosesearching for love and romance, expressions of opinions/sentiments about Philippines/Japan on the Net, and religious or spiritual information.

In contrast, the following item was relatively unappealing among the respondents: get financial information.

For social capital items, the following comparatively scored high among respondents: Filipinos getting to know each other, living an easier life in Japan, feeling proud of being Filipino, belonging to a community, being active to a local communities, trusting people and being more religious. 


\section{Social Capital and Educational Level, Age, Gender and Income}

The means of social capital items vis-à-vis educational levels (high school, some college/vocational, college/postgraduate), age, gender and income of respondents were analyzed.

Two items from social capital were significant with educational levels: Are you more religious because of these online forums? $(\mathrm{t}(12.88)=.466, \mathrm{p}<.05)$ and Is living in Japan easier, thanks to these online forums? $(\mathrm{t}(39.441)=3.28, \mathrm{p}<.001)$.

One way ANOVA was also conducted to analyze social capital items' means between educational levels, gender and income. Statistically significant differences were found among the following items: Do you belong to a community, thanks to online forums? $(\mathrm{F}(2$, $87)=3.96, \mathrm{p}<.05)$, Do you feel proud to be Filipino through these online forums? $(\mathrm{F}(2$, $87)=4.62, \mathrm{p}<.05)$, Have online forums helped you to get to know more Filipinos? $(\mathrm{F}(5$, $84)=2.08, \mathrm{p}<.05)$, Do you trust people online from online forums? $(\mathrm{F}(5,84)=3.80, \mathrm{p}<.05)$, Are you active in local communities because of online forums? $(F(5,84)=2.40, p<.05)$, and Is living in Japan easier, thanks to these online forums? $(\mathrm{F}(5,84)=2.06, \mathrm{p}<.05)$.

Table 3 presents the means and SD for social capital online and education.

Table 3 Means and SD for Social Capital Online and Education ( $\mathrm{N}=90)$

\begin{tabular}{|c|c|c|c|c|c|c|c|c|}
\hline & \multicolumn{2}{|c|}{$\begin{array}{l}H S \\
n=9\end{array}$} & \multicolumn{2}{|c|}{$\begin{array}{l}S C / V \\
n=30\end{array}$} & \multicolumn{2}{|c|}{$\begin{array}{l}C / P G \\
n=51\end{array}$} & \multicolumn{2}{|c|}{$\begin{array}{l}\text { Total } \\
\mathrm{N}=90\end{array}$} \\
\hline & $M$ & SD & $M$ & SD & $M$ & $S D$ & $M$ & $S D$ \\
\hline 1.) Have online forums helped you to get to know more Filipinos? & 4.56 & 7.3 & 4.3 & 0.99 & 4.02 & 0.99 & 4.17 & 0.97 \\
\hline 2.) Do you trust people from online forums? & 2.78 & 1.3 & 3.43 & 1.1 & 2.88 & 1.12 & 3.06 & 1.16 \\
\hline 3.) Do you belong in a community, thanks to online forums? & 4.22 & 0.7 & 4.23 & 1 & 3.69 & 0.88 & 3.92 & 0.939 \\
\hline 4.) Are you active in local communities because of online forums? & 3.44 & 1 & 3.33 & 1.18 & 3.04 & 1.3 & 3.18 & 1.22 \\
\hline 5.) Do you feel proud to be Filipino because of online forums? & 4.44 & 0.9 & 4.68 & 0.71 & 4.06 & 0.97 & 4.3 & 0.92 \\
\hline 6.) Are you more religious because of online forums? & 3 & 1.1 & 3.37 & 1.5 & 2.8 & 1.4 & 3.01 & 1.4 \\
\hline 7.) Is living in Japan easier, thanks to online forums? & 4.89 & 0.3 & 4.4 & 0.81 & 4.29 & 1 & 4.39 & 0.92 \\
\hline
\end{tabular}

In comparing the means between the educational level, high school (HS) graduates have a significantly higher mean than college/post graduate graduates or level (C/PG) for social capital online items: Have online forums helped you to get to know more Filipinos? and Is 
living in Japan easier, thanks to online forums?. Some college/vocational graduates (SC/V) meanwhile have significantly higher mean for social capital online items: Do you belong in a community, thanks to online forums? and Do you feel proud to be Filipino because of online forums?. The total mean scores of each item revealed how Filipino migrant users have significantly high social capital online.

As for social capital and age groups, respondents from the 36-41 age group have a notably higher mean on social capital online items: Have online forums helped you to get to know more Filipinos? Are you active in local communities because of online forums and Is living in Japan easier, thanks to online forums? Meanwhile, 42-over age group respondents have a higher mean on items: Do you belong to a community, thanks to online forums and Are you more religious because of online forums. This finding on being religious through online forums is substantiated by some case studies that would indicate that people who are getting older are more concerned about their spiritual and religious fulfillment than those who are young (Momtaz, et.al., 2010; Brown \& Tierney, 2009). The 18-23 age group respondents, in the interim, have aappreciably higher mean on social capital online items: Do you trust people from online forums and Do you feel proud to be Filipino because of online forums? As this age group is still volatile and impulsive in terms of their dealings with people, most often than not, they easily trust and are persuaded by other people (Rotenberg, et.al., 2010). In sum, the total mean scores on social capital vis-à-vis age groups are relatively high. Below is the table for means and SD for social capital online and age groups.

Table 4 provides the means and SD for social capital online and age groups.

\begin{tabular}{|c|c|c|c|c|c|c|c|c|c|c|c|c|}
\hline \multirow[t]{4}{*}{ Table 4 Means and SD for Social Capital Online and Age Group } & \multicolumn{4}{|c|}{$(\mathrm{N}=90)$} & \multirow{3}{*}{\multicolumn{2}{|c|}{$\begin{array}{l}30-35 \\
n=31 \\
\end{array}$}} & \multirow{3}{*}{\multicolumn{2}{|c|}{$\begin{array}{l}36-41 \\
n=7\end{array}$}} & \multirow{3}{*}{\multicolumn{2}{|c|}{$\begin{array}{c}\text { 42-over } \\
n=4\end{array}$}} & \multirow{3}{*}{\multicolumn{2}{|c|}{$\begin{array}{l}\text { Total } \\
\mathrm{N}=90\end{array}$}} \\
\hline & \multirow{2}{*}{\multicolumn{2}{|c|}{$\begin{array}{l}18-23 \\
n=8\end{array}$}} & \multirow{2}{*}{\multicolumn{2}{|c|}{$\begin{array}{l}24-29 \\
n=40\end{array}$}} & & & & & & & & \\
\hline & & & & & & & & & & & & \\
\hline & M & SD & M & SD & M & SD & M & SD & M & SD & M & SD \\
\hline 1.) Have online forums helped you to get to know more Filipinc & 4.56 & 0.73 & 4.03 & 0.99 & 4.1 & 1 & 4.63 & 0.7 & 4 & 1.41 & 4.17 & 0.97 \\
\hline 2.) Do you trust people from online forums? & 3.67 & 1.5 & 2.82 & 1.05 & 3.1 & 1.15 & 3.25 & 1.3 & 3.25 & 0.96 & 3.06 & 1.16 \\
\hline 3.) Do you belong in a community, thanks to online forums? & 4.22 & 1.09 & 3.74 & 0.99 & 4 & 0.89 & 4.13 & 0.8 & 4.25 & 0.5 & 3.92 & 0.94 \\
\hline 4.) Are you active in local communities because of online forun & 3.67 & 1.5 & 2.85 & 1.14 & 3.2 & 1.186 & 4.13 & 1.1 & 3.25 & 0.96 & 3.18 & 1.22 \\
\hline 5.) Do you feel proud to be Filipino because of online forums? & 4.67 & 0.71 & 4.28 & 0.83 & 4.1 & 1.125 & 4.5 & 0.8 & 4.75 & 0.5 & 4.3 & 0.92 \\
\hline 6.) Are you more religious because of online forums? & 3.89 & 1.45 & 2.62 & 1.27 & 3.2 & 1.349 & 2.75 & 1.8 & 4 & 1.16 & 3.01 & 1.4 \\
\hline 7.) Is living in Japan easier, thanks to online forums? & 4.44 & 0.88 & 4.36 & 0.93 & 4.3 & 1.022 & 4.88 & 0.4 & 4.25 & 0.96 & 4.39 & 0.92 \\
\hline
\end{tabular}


Table 5 meanwhile presents the means and SD for social capital online and gender. Though there were more female respondents who took time to answer the questionnaire, males have considerably higher means for social capital online items. Campbell and Rosenfeld (1985) validated this finding as it found that males have larger networks than females. Female respondents, meanwhile, felt prouder of being Filipinos because of online forums. Though some studies would point out that being male or female does not have any bearing in terms of social capital online (Ellison, et.al..,2007; 2006) in this case, however, males have significant higher social capital online than females.

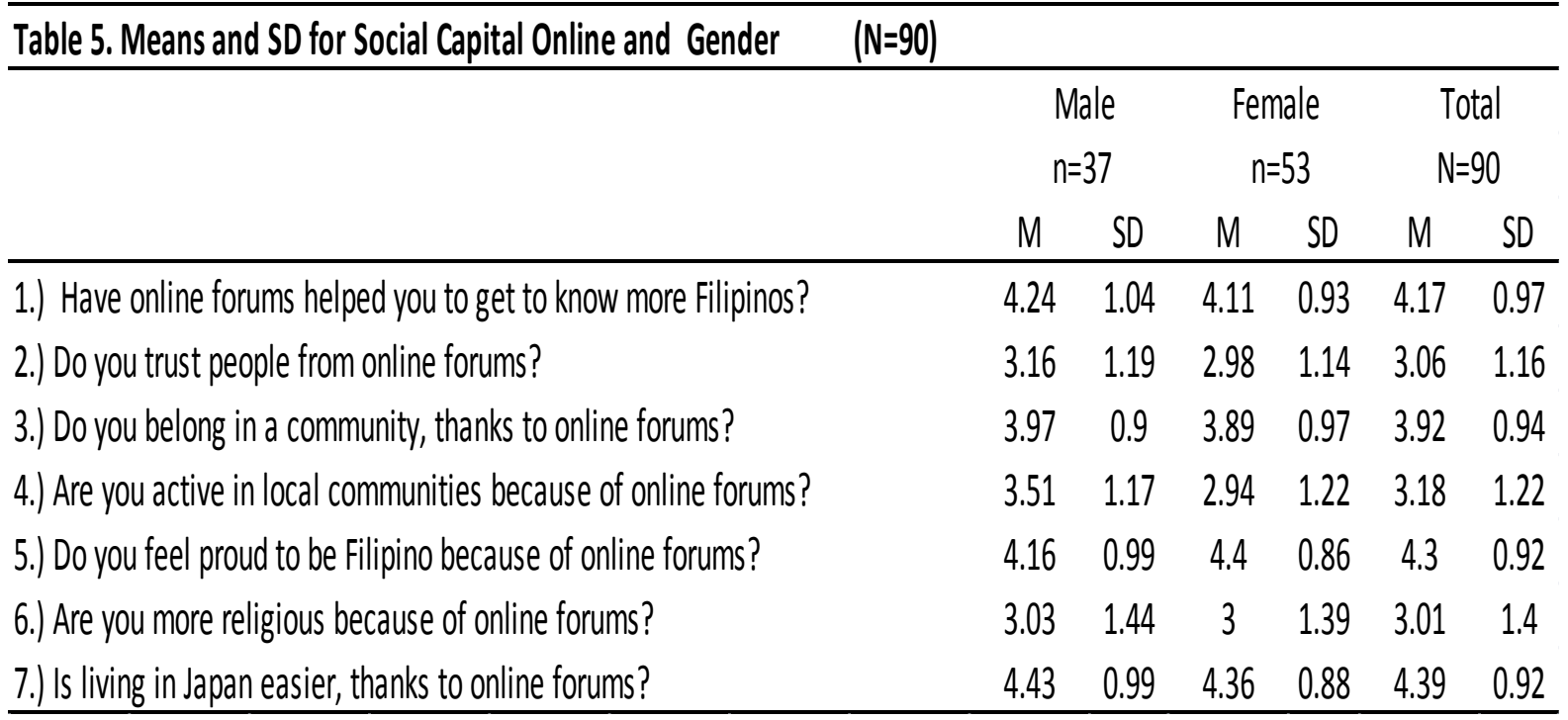

In comparing the means between social capital online and income, it could be surmised from Table 6 that, those who have a higher income range, 250,001-300K yen and over 300K yen, have higher social capital online. Items on how online forums helped individuals to get to know more Filipinos and on feeling proud of being Filipinos because of online forums were highly favored because of the perfect mean and almost perfect mean marked by these two income groups. This could be attributed, most probably, to the fact that those who have higher income would have more time and resources to access the Internet than those who are in the lower income bracket. This is so since lower income bracket individuals would concentrate more on finding another job to better their income levels. 
Table 6 Means and SD for Social Capital Online and Income (N=90)

less 100K 100-150K 150,001-200 200,001-250K 250,001-300K over 300K Total

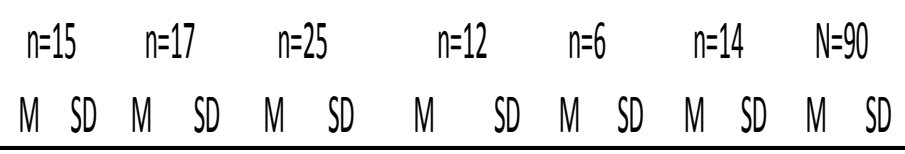

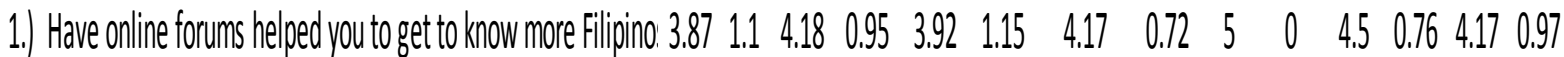

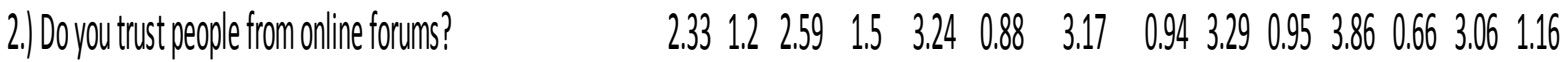

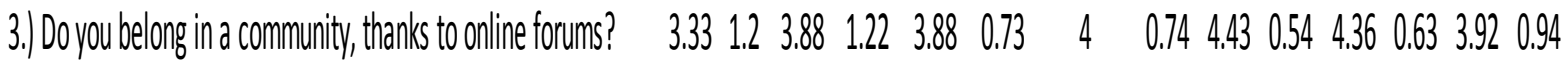

4.) Are you active in local communities because of online forum $2.33 \quad 1.42 .94 \quad 1.56 \quad 3.12 \quad 0.88 \quad 3.83 \quad 0.94 \quad 3.86 \quad 0.693 .57 \quad 1.02 \quad 3.181 .22$

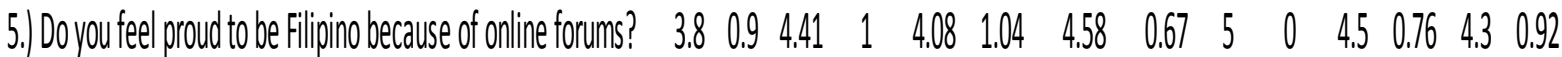

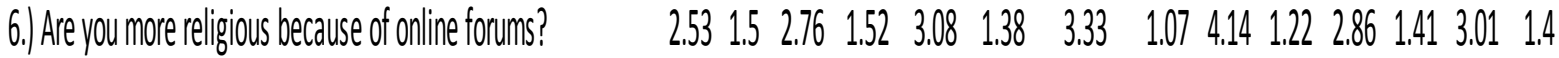

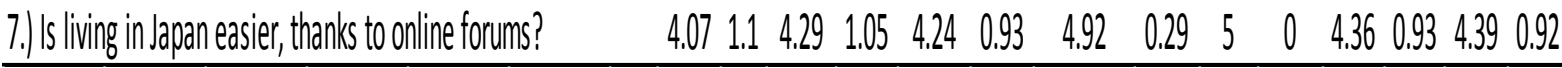

By and large, the total means and SDs of each item on social capital and key demographic attributes such as educational level, age, and gender showed how Filipino migrant users have significantly high social capital online.

The relation between Internet use, communication and social capital is also evident in most of the items relevant to this paper. As Table 7 indicates, items on being more religious have significant correlations to all items that pertain to Internet use. This then corresponds to the analysis of Cheong, P. and Poon, JPH (2008)'s study in which the Internet is becoming a popular medium to maintain and enhance religiosity. Moreover, online communities have been of great help for migrants to know other migrants and most of the items on Internet use have significant correlation to social capital online.

It should be noted, as well, that living in Japan has become easier because online forums have become crucial in becoming a platform to seek advice for visa and legal issues and expressing opinions and sentiments about the Philippines and/or Japan online. This is in addition to the fact that these online communities have been conduits for information resources on news within and outside the host society. These viewpoints have given migrants the proper knowledge and perspective on how to live and settle well in Japan. 
The findings of the study provide a positive relationship between Internet use, communication and social capital among Filipino migrants in Japan. Through online communities (i.e. Timog.com and Malago.net), migrants are equipped with information and knowledge on certain services, products, issues and events. In the case of those who do not have jobs, online users rely heavily on the Internet for prospective employment vacancies. They are also on the lookout for job opportunities from their cyber communities through their fellow online users. This is so since there are members who post jobs or recruit online can also ask their networks if they are available jobs for his/her perusal. The use of Internet saves the time, money and energy of going through the hassle of being physically present for finding jobs in physical sites or locations.

Timog Online and Malago.net provided venues for Filipino migrants to communicate and interact with each other. It is amazing that what used to be a medium for simple exchanges of hello's has become a great potential for gaining information and support from fellow Filipino migrants in Japan. These cyber communities have ensured daily updates of the Philippines as well as the latest news in Japan. This has forged ties between and among Filipinos and considerably paved the way for online participants to feel cared about in the way a face-to-face conversation would allow. The Internet has created a way in which people who have not seen each other or who are unfamiliar to each other but united because of their national identity, can be connected and create a sense of belonging thus enhancing social relationships

Table 7. Correlations between Internet Use and Social Capital

\begin{tabular}{|l|l|l|l|l|l|l|l|}
\hline & $\begin{array}{l}\text { Helped } \\
\text { to get }\end{array}$ & Trust & Belong & Active in & Feel & More & Livin \\
to & e & in a & local & proud & religio & g in \\
know & from & ity & communit & to be & us & Japan \\
ies & Filipi & & easie \\
Filipin & enlin & thanks to & & no & & r \\
os & foru & forums & & & & thank \\
ms & & & & & & s to \\
onlin
\end{tabular}




\begin{tabular}{|c|c|c|c|c|c|c|c|}
\hline & & & & & & & $\begin{array}{l}\text { foru } \\
\mathrm{ms}\end{array}$ \\
\hline 1. Get news & $.38^{* *}$ & .05 & $.25^{* *}$ & .17 & .21 & .15 & $.36^{* *}$ \\
\hline $\begin{array}{l}\text { 2. Get financial } \\
\text { information }\end{array}$ & $.22 * *$ & .17 & $.27 * *$ & $.46^{* *}$ & $.02^{*}$ & $.52 * *$ & .20 \\
\hline $\begin{array}{l}\text { 3. Look for } \\
\text { information } \\
\text { about product }\end{array}$ & $.23^{*}$ & .17 & .19 & .04 & .10 & $.37 * *$ & .18 \\
\hline $\begin{array}{l}\text { 4. Get } \\
\text { information } \\
\text { about travel }\end{array}$ & .15 & .2 & $.27 * *$ & .02 & .15 & $.52 * *$ & .16 \\
\hline $\begin{array}{l}\text { 5. Do research } \\
\text { for school or } \\
\text { training }\end{array}$ & $.28^{* *}$ & -.01 & -.02 & -.07 & .15 & $.36^{* *}$ & .13 \\
\hline $\begin{array}{l}\text { 6. Look for } \\
\text { health and } \\
\text { medical } \\
\text { information }\end{array}$ & $.31 * *$ & .96 & .07 & -.06 & .11 & $.39 * *$ & .18 \\
\hline $\begin{array}{l}\text { 7. Look for jobs } \\
\text { or spiritual } \\
\text { information }\end{array}$ & $.27^{* *}$ & .09 & -.01 & -.1 & .05 & $.39 * *$ & 0 \\
\hline $\begin{array}{l}\text { 8. Look for } \\
\text { religious or } \\
\text { spirtual } \\
\text { information }\end{array}$ & $.29 * *$ & $.32^{* * *}$ & .12 & .03 & .16 & $.43 * *$ & .15 \\
\hline $\begin{array}{l}\text { 9. Ask for } \\
\text { advice on visa } \\
\text { and legal issues }\end{array}$ & $.34 * *$ & $.32 * *$ & $.33^{* * *}$ & $.27 * *$ & $.32 * *$ & $.50^{* *}$ & $.22^{* * *}$ \\
\hline $\begin{array}{l}\text { 10. Espress } \\
\text { opinions/sentim } \\
\text { ents about } \\
\text { Phil/Japan }\end{array}$ & $.4^{* *}$ & $.33^{* * *}$ & $.26^{* *}$ & $.39 * *$ & $.24 *$ & $.47 * *$ & $.26^{*}$ \\
\hline
\end{tabular}




\begin{tabular}{|l|l|l|l|l|l|l|l|}
$\begin{array}{l}11 . \text { Use Internet } \\
\text { for love and } \\
\text { romance }\end{array}$ & $.38^{* *}$ & $.41^{* *}$ & $.35^{* *}$ & .18 & $.30^{* *}$ & $.43^{* *}$ & .28 \\
\hline
\end{tabular}

*Correlation is significant at 0.05 level (2-tailed).

**Correlation is significant at the 0.01 level (2-tailed).

\section{Reliability of Variable Measures}

For the 11 items on Internet use that were measured using a Likert-type 5 point scale and were reverse coded for analysis, relatively a high reliability was found based on Cronbach's Alpha $=.88$. In the same manner, the seven items on social capital measured through a Likert-type 5 point scale, reverse-coded for analysis, relatively a high reliability was found based on Cronbach's Alpha $=.85$

\section{Conclusion}

The results of the survey revealed that Filipino migrants' appropriation of the Internet has an affirmative connection to the concept of social capital and communication. Given the internal and external stresses that migrants go through, the Internet has become a haven for Filipinos to (re)create their national identity and community. The Internet has fortified communication and the cultivation of social capital. This has instigated a solidarity network among the Filipino diaspora in Japan.

As explicated in the survey results, these interactions which are based on social trust, cooperation and relationship of online users ultimately generated social capital. Needless to say, the more people engage, relate, network with one another, the denser the level of social capital developed through this interaction online. Here, the researcher could surmise that the Internet has given migrants the ability to reproduce, re-create and maintain their sense of being Filipinos despite their absence from the homeland. These online communities have paved the way for the Filipino need for belongingand kinship to exist in foreign land.

As this paper only focuses on online surveys, the researcher believes an offline component should be put in place so that there is a comparative analysis of virtual and actual 
communities. In this way, differences and similarities will be laid out, and a study of the connection between online and offline ties may also be considered.

Since this serves as a benchmark on the study of the Filipino diaspora in Japan, the Internet, communication and social capital, the researcher believes that separate qualitative and quantitative research should be conducted. The qualitative aspect should delve more into the conduct of Internet ethnography so as to provide depth and breadth on the topic of inquiry. The quantitative aspect, on the other hand, should have extensive online surveys and provide ways of how to attract more online users to participate in the research. 


\section{References}

Abrera-Mangahas, M. (1987).Filipino Overseas Migration: Focus on 1975-1986. Scalabrini Migration Center.

Alegado, D. (1996). Carl Damaso: A Champion of Hawaii's Working People. In John Okamura (Guest Editor), Filipino American History: Identity and Community in Hawaii. Honolulu: Social Process in Hawaii, vol. 37: 2635.

Anderson, J. (1999). Filipina migration to Japan: Hostesses, house helpers, and homemakers. Filipinas 33: 57-74.

Ballescas, Ma. Rosario Piquero. 2003. Filipino migration to Japan, 1970s to 1990s. In SetsuhoIkehata and Lydia N. Yu Jose (Eds.), Philippines-Japan relations (546575).Quezon City: Ateneo de Manila University Press.

Baym, Nancy K. 2000. Tune In, Log On: Soaps, Fandom, and On-Line Community. Thousand Oaks , California : Sage.

Brown, P., \& Tierney, B.. (2009). Religion and subjective well-being among the elderly in China. Journal of Socio - Economics, 38(2), 310. Retrieved October 2, 2010, from ABI/INFORM Global.

Campbell, K.E., Rosenfeld, R.A. (1985). Job search and job mobility: sex and race differences. In R.L. Simpson and I. H. Simpson (Eds.), Research in the Sociology of Work, Vol 3,(147-174). Greenwich, CT: JAI Press.

Castles, S. (2000). Ethnicity and globalization. London: Sage.

Catholic Bishops Conference of the Philippines (CBCP).Manila Archdiocese launches

'Catextism .' Retrieved March 21, 2008, from

http://www.cbcponline.org/news/Archives/may2002/news6-may5.html

Cheong, P.H. \& Poon, J.P.H. (2008). 'WWW.Faith.Org': (Re)structuring Communication and Social Capital Building among Religious Organizations.Information, Communication and Society, 11 (1), 89-110.

Collado, P. (2003). Who are the overseas Filipino workers? In M. Tsuda (Ed.), Filipino diaspora: demography, social networks, empowerment and culture (pp. 23-40). Manila: Philippine Migration Research Network and Philippine Social Science Council.

Connell, J. (1993). Kitanai, Kitsui and Kiken: The Rise of Labour Migration to Japan, Economic \& Regional Restructuring Research Unit, University of Sydney. 
Diamandaki, K. (2003). Virtual Ethnicity and Digital Diasporas: Identity Construction in Cyber-space. In Global Media Journal. 2. 2. Retrieved June 3, 2009, from http://lass.calumet.purdue.edu/cca/gmi/-sp03/-graudatesp03/gmj-sp03

Ellison, N, Steinfield C and C. Lampe. (2006). The Role of Facebook: Spatially Bounded Online Social Networks and Social Capital. Paper Presented at the Annual Conference of the International Communication Association, Dresden Germany. Ellison, N. B., Steinfield, C., \& Lampe, C. (2007). The benefits of Facebook "friends:" Social capital and college students use of online social network sites. Journal of Computer-Mediated Communication, 12, 1143-1168.

Ellison, N. B., Steinfield, C., \& Lampe, C. (2007). The benefits of Facebook "friends:" Social capital and college students use of online social network sites. Journal of Computer-Mediated Communication, 12, 1143-1168.

Ferlander, Sara. (2003). The Internet, Social Capital and Local Community. Unpublished doctoral dissertation, University of Stirling, Scotland.

Hewitt, P. (2003). The Gray Roots of Japan's Crisis.Asia Program Special Report .Woodrow Wilson International Center for Scholars. Retrieved January 23, 2009 from http://www.iun.edu/ hisdcl/h207_2002/japanagingsociety.pdf.

International Telecommunication Union. (2009). http://www.itu.int/en/pages/default.aspx Internet World Statistics.(2009). Statistics on Asia.

http://www.internetworldstats.com/asia/jp.htm

Katz, J. E. and Rice, R. E. (2002).Social consequences of Internet use: Access, involvement and interaction.Cambridge, MA: The MIT Press.

Lin, N. (2001). Social capital: A theory of social structure and action. New York: Cambridge University Press.

Mann, C. \& Stewart F. (2005).Internet Communication and Qualitative Research: A Handbook for Researching Online. London: SAGE Publications, Inc.

McCreedy, A. (2003). The Demographic Dilemma: Japan's Aging Society. Asia Program Special Report.Woodrow Wilson International Center for Scholars. Retrieved January 23, 2009 from http://www.iun.edu/ hisdcl/h207_2002/japanagingsociety.pdf.

Mcluhan, M. (1964). Understanding Media: The Extensions of Man. NY: McGraw Hill. 
Melican, N. (2010, September). Nurse group bats for

JPEPAreview. BusinessWorld. Retrieved September 21, 2010, from ProQuest

Newsstand.

Momtaz, Y., Ibrahim, R., Hamid, T., \& Yahaya, N.. (2010). Mediating Effects of Social and Personal Religiosity on the Psychological Well Being of Widowed Elderly

People. Omega, 61(2), 145. Retrieved October 2, 2010, from Research Library.

Onuki, H.. (2009). Care, Social (Re)production and Global Labour Migration: Japan's 'Special Gift' toward 'Innately Gifted' Filipino Workers. New Political Economy, 14(4), 489. Retrieved September 21, 2010, from ABI/INFORM Global.

Parham, A. (2004). Diaspora, community and communication: Internet use in transnational Haiti. Global Networks 4(2): 199-217.

Parrenas, R. (2001). Servants of Globalization: Women, Migration, and Domestic Work. US: Stanford University Press.

Putnam, R. (2000). Bowling Alone: The Collapse and revival of American Community. New York: Simon \& Schuster.

Putnam, R. D. (2004). Bowling together.OECD Observer. Retrieved Novemeber15, 2009, from http://www.oecdobserver.org/news/fullstory.php/aid/1215/Bowling_together.html.

Rheingold, H. (1993). Homesteading on the Electronic Frontier. Reading, MA: AddisonWesley.

Ribas-Mateos, N., Basa, C. \& de la Rosa, J. (2008).Gender, remittances and development: The case of Filipino migration to Italy. Final abbreviated fieldwork report, United Nations Instraw, Santo Domingo.

Robson, C. (2002). Real World Research: A Resource for Social Scientists and PractitionerResearchers ( $2^{\text {nd }}$ Edition). USA: Blackwell Publishing.

Rotenberg, K., Addis, N., Betts, L., Corrigan, A., Fox, C., Hobson, Z., Rennison, S., Truema n, M., \& Boulton, M.. (2010). The Relation Between Trust Beliefs and Loneliness During Early Childhood, Middle Childhood, and Adulthood. Personality and Social Psychology Bulletin, 36(8), 1086. Retrieved October 2, 2010, from Research Library.

Shimada, H. (1994) Japan's “Guest Workers”:Issues and Public Policies. Tokyo:University of Tokyo Press. 
Usui, C. (2003). Japan's Aging Dilemma? Asia Program Special Report . Woodrow Wilson International Center for Scholars. Retrieved January 23, 2009 from http://www.iun.edu/ hisdcl/h207_2002/japanagingsociety.pdf.

Waldinger, R. \&Lichter, M.I. (2003).How the Other Half Works: Immigration and the Social Organization of Labor. Berkeley: University of California Press. 